\title{
ПАССИВНАЯ ОРТОСТАТИЧЕСКАЯ ПРОБА В ДИАГНОСТИКЕ СИНКОПАЛЬНЫХ СОСТОЯНИЙ
}

\author{
Чепчерук О.Г. ${ }^{1}$ Глуховской Д.В. ${ }^{,}$Наумов К.М. ${ }^{1}$, Золотарева Н.А. ${ }^{2}$ \\ ${ }^{1}$ ВМедА им. С.М. Кирова, \\ ${ }^{2}$ Филиал №5 442 ВКГ, Санкт-Петербург
}

Синкопальные состояния (обмороки, синкопе) - мультидисциплинарная проблема практической медицины. В структуре причин транзиторной утраты сознания вазовагальные синкопе занимают доминирующие позиции по частоте распространенности и необходимости принятия специализированных лечебно-профилактических решений $[1,2,3]$. По данным исследования SUP (Syncope Unit Project), основанном на анализе сведений, поступивших от 9 специализированных отделений по ведению лиц, испытавших синкопальные состояния, было показано, что $67 \%$ обмороков имели рефлекторную природу, в 4\% случаев обмороки носили ортостатический характер, в $6 \%$ - кардиогенный, у 5\% лиц была констатирована утрата сознания несинкопального происхождения. У $18 \%$ испытавших падение субъектов генез отключения сознания остался неизвестным [1].

Синкопальное состояние - транзиторная потеря сознания, возникающая ввиду церебральной гипоперфузии, характеризующаяся резким началом, кратковременностью и спонтанным восстановлением [4]. Актуальность данной проблемы состоит в том, что по данным разных источников, как зарубежных, так и отечественных, распространенность обмороков колеблется от 30 до $50 \%$ среди всей взрослой популяции людей. Доля пациентов, испытавших эпизод кратковременной утраты сознания и вследствие этого госпитализированных в различные учреждения, составляет менее $50 \%$.В приемные отделения такие пациенты поступают в $10 \%$ случаев. Около 1-5\% всех обращений в отделения неотложной помощи в США составляют обмороки [5]. Подразделение синкопальных состояний по этиологии, рекомендуемое экспертами ESC (2018), предполагает следующие формы.

1. Рефлекторные (нейрогенно-опосредованные)

- вазовагальные

- ситуационные

- синдром каротидного синуса

- атипичные формы, например, индуцированные тилт-тестом

2. Ортостатическая гипотензия (синкопе)

- вследствие первичной автономной недостаточности (патология центральной нервной системы)

- вследствие вторичной автономной недостаточности (нейропатии и др.)

- лекарственно-индуцированные ортостатические реакции (вазодилататоры, ингибиторы моноаминооксидазы (МАO) и др.)

- вследствие уменьшения объёма циркулирующей крови (анемия, рвота, диарея)

3. Кардиальные или кардиоваскулярные

- нарушения сердечного ритма как первичная причина (брадиаритмии, тахиаритмии, лекарственноиндуцированные аритмии)

- структурные заболевания (аортальный стеноз, гипертрофическая кардиомиопатия, миксома предсердия, тромбоэмболия лёгочной артерии и другие).

Первичный скрининговый подход, включающий детальный сбор анамнеза, физикальное исследование, регистрацию стандартной 12-канальной электрокардиограммы (ЭКГ), эхокардиографию, внутригоспитальный мониторинг ритма, консультацию невролога, общеклинический и рутинный биохимический анализы крови, позволяет прийти к определённому диагностическому заключению. Пациенты, испытавшие транзиторную утрату сознания и не подвергнутые должному диагностическому минимуму, характеризуются достоверно большим риском летального исхода (>4\%) в течение последующего месяца по сравнению с лицами, у которых были выполнены необходимые скрининговые диагностические процедуры $(<1 \%)$. В диагностике обмороков неясного генеза важную роль играет длительная пассивная ортостатическая проба (тилт-тест). В скрининговой диагностике предположительно рефлекторного генеза транзиторной утраты сознания важную роль играют провокационные тесты (в частности, тилт-тест и массаж каротидного синуса), которые особенно уместны в случае атипичной манифестации эпизода. Последние нацелены на воспроизведение в лабораторных условиях обморока и уточнение связанных с ним особенностей. Идея такого подхода основана на выявлении возможной идентичности механизма реализации обморока в искусственных условиях и в процессе повседневной жизнедеятельности.

На основе анализа результатов двух больших многоцентровых исследований, M. Brignole et al. (2012) показали, что в ходе первоначального скрининга причину транзиторной утраты сознания удается распознать у $50 \%$ лиц, доставленных после эпизода отключения в отделения неотложной помощи, и ещё у $20 \%$ пациентов (т.н. диагностически трудных), если в качестве учреждения первого контакта выступает специализированный центр. целесообразность применения различных диагностических методик, включая длительную пассивную ортостатическую пробу (тилт-тест), во многом зависит от принадлежности пациента к той или иной социо-демографической группе, а также особенностей задач исследований. Важно определить предрасположенность к определенным типам синкопальных состояний и вероятность участия нарушений сердечного ритма и проводимости в их воз- 
никновении. Так, тилт-тест воссоздаёт длительный пассивный постуральный стресс для определения наличия у пациента автономного субстрата нейрорефлекторного обморока. Вазовагальный рефлекс, который по существу реализует транзиторную утрату сознания, может быть усилен лекарственными препаратами, такими как изопротеренол, нитроглицерин и кломипрамин [6]. Тем не менее, фармакологические пробы с названными препаратами, повышая чувствительность тилт-теста, снижают его специфичность. Положительный ответ на пассивный ортостаз определяется возникновением клиники пресинкопального состояния или полной утраты сознания, связанной с гипотензией и/или брадикардией (асистолией). Нейрокардиогенные синкопе, индуцируемые при помощи пассивного ортостаза, могут развиваться по трем вариантам: кардиоингибиторному (ведущим признаком является брадикардия, иногда сменяющаяся асистолией), вазодепрессорному (артериальная гипотензия без уменьшения ЧСС) или смешанному.

В консенсусе экспертов Европейского общества сердечного ритма (2015) определены современные позиции применительно к валидности длительной пассивной ортостатической пробы и имплантации петлевого регистратора ЭКГ [2]. Польза тилт-тестинга считается доказанной при: 1) дифференциальной диагностике синкопального состояния с судорожным компонентом от настоящих судорожных припадков; 2) неясности причины обморока несмотря на тщательный сбор анамнеза; 3) необходимости самого факта уточнения диагноза синкопального состояния.

Синкопальные состояния имеют большое междисциплинарное клиническое значение и должны рассматриваться преимущественно с позиций исключения наиболее грозных причин - кардиоваскулярных и неврологических заболеваний. Вместе с тем, явное преобладание рефлекторных обмороков в структуре транзиторных утрат сознания указывает на высокую вероятность наличия таковых в случае необнаружения признаков органического поражения сердечно-сосудистой системы, заболеваний (состояний)-поставщиков ортостатической гипотензии (сахарного диабета, болезней ЦНС, нейропатий различного генеза), исключения эпилепсии. Первичный скрининговый поиск причин транзиторных утрат сознания, осуществляемый в диагностических подразделениях многопрофильных клиник, специализирующихся в данной области, позволяет с высокой вероятностью установить доминирующий механизм развития обморока [6].

\section{Литература}

1. Brignole, M. Prospective multicenter systematic guideline-based management of patients referred to the syncope units of general hospitals / M. Brignole [et al.] // Europace. - 2010. - Vol. 12., Iss. 1 - P.109-118.

2. Sheldon, R. 2015 heart rhythm society expert consensus statement on the diagnosis and treatment of postural tachycardia syndrome, inappropriate sinus tachycardia, and vasovagal syncope / Sheldon R.S., Grubb B.P., Olshansky B. [et al.] // Heart Rhythm. -2015. - Vol.12, Iss. 6. - P.e41-e63.

3. Sutton, R. International Study on Syncope of Uncertain Etiology 3 (ISSUE-3) Investigators Cardiac pacing in patients with neurally mediated syncope and documented asystole: effectiveness analysis from the Third International Study on Syncope of Uncertain Etiology (ISSUE-3) Registry / R.Sutton, A.Ungar, P. Sgobino [et al.] // Europace. - 2014. - Vol.16, Iss.4 - P. 595-599.

4. Brignole, M. 2018 ESC Guidelines for the diagnosis and management of syncope /M. Brignole [et al.] // European Heart Journal. - 2018. - Vol. 39, Iss. 21 - P. 1883-1948.

5. Sheldon, R. Diagnostic criteria for vasovagal syncope based on a quantitative history / R. Sheldon, S. Rose, S. Connolly et al. // European Heart Journal. - 2006. - Vol.27. - P. 344-350.

6. Барсуков, А.В. Синкопальные состояния как сфера профессиональных интересов врача-кардиолога / А. В. Барсуков, Д.В. Глуховской, О.Г. Чепчерук и [et al.] // Вестник Российской Военно-Медицинской Академии. - 2016. - 3(55). - С. $251-259$.

DOI 10.32863/1682-7392-2018-3-63-114-115 